DOI: https://doi.org/10.15407/techned2018.06 $: \underline{005}$

\title{
SIMULATION OF NONLINEAR SKIN EFFECT UNDER SINUSOIDAL VOLTAGE SUPPLY BY USING HARMONIC BALANCE FINITE ELEMENT METHOD AND EFFECTIVE MAGNETIC CURVES
}

$\quad$ Journal
Publisher
ISSN
Issue
Pages

\author{
Tekhnichna elektrodynamika \\ Institute of Electrodynamics National Academy of Science of Ukraine \\ 1607-7970 (print), 2218-1903 (online) \\ No 6, 2018 (November/December) \\ $5-8$
}

\begin{abstract}
Author
I.S. Petukhov*

Institute of Electrodynamics National Academy of Sciences of Ukraine, pr. Peremohy, 56, Kyiv, 03057, Ukraine, e-mail: igor_petu@ukr.net

* ORCID ID : http://orcid.org/0000-0003-1416-1174
\end{abstract}

\section{Abstract}

The nonlinear model of the time-periodic magnetic field in a conducting ferromagnetic medium is presented. The model is based on the combined use of the harmonic balance method and the finite element method. The case of magnetic field excitation by alternating sinusoidal voltage is considered. The values of eddy current losses are compared. They are determined using the method as well as monoharmonic approach with normal magnetization curve and the effective magnetic curves. It is determined that monoharmonic approach with normal magnetization curve gives the eddy current losses greater by about $9 \%$ than the losses obtained by harmonic 
balance method. The monoharmonic approach using effective magnetization curves gives much smaller specific eddy current losses. References 6 , figures 3.

Key words: harmonic balance method, finite element method, ferromagnetic conducting medium, eddy current losses.

Received: 02.03 .2018

Accepted: 22.03 .2018

Published: 23.10 .2018

\section{References}

1. ANSYS Mechanical APDL Low-Frequency Electromagnetic Analysis Guide. ANSYS, Inc. Release 14.5 Southpointe October 2012. URL: http://www.ansys.com/staticassets/ANSYS/Con ference/Confidence/Houston/Downloads/structural-mechanics-145.pdf

2. Effective Nonlinear Magnetic Curves Calculator. Created in COMSOL Multiphysics 5.2. URL: https://www.comsol.com/model/download/263211/applications.effective nonlinear magnetic C urves.pdf

3. Bachinger F., Langery U., Schoberl J. Efficient Solvers for Nonlinear Time-Periodic Eddy Current Problems. Comput. Visual Sci. 2006. Vol. 9(4). Pp. 197-207. DOI: https://doi.org/10.1 007/s00791-006-0023-Z

4. Lu J., Zhao X., Yamada S. Harmonic Balance Finite Element Method: Applications in Nonlinear Electromagnetics and Power Systems. Wiley-IEEE Press, 2016. 304 p. DOI: https:/ /doi.org/10.1002/9781118975770

5. Petukhov I.S. Simulation of alternating electromagnetic field in a conducting ferromagnetic medium by finite element method. Tekhnichna Elektrodynamika. 2008. No 4. Pp. 18-26. (Rus) 6. Petukhov I.S. Consideration of the nonlinear properties of the medium in calculating the heat release from eddy currents in a ferromagnet by a differential harmonic method. Pratsi 
Instytutu elektrodynamiki NAS of Ukraine

. 2016. No 43. Pp. 118-124. (Rus)

PDF 